\title{
Skeletal muscle adiposity is associated with physical activity, exercise capacity and fibre shift in COPD
}

\author{
Matthew Maddocks ${ }^{1,2,5}$, Dinesh Shrikrishna ${ }^{3,5}$, Simone Vitoriano ${ }^{1,2}$, \\ Samantha A. Natanek ${ }^{3}$, Rebecca J. Tanner ${ }^{3}$, Nicholas Hart ${ }^{4}$, Paul R. Kemp ${ }^{3}$, \\ John Moxham ${ }^{1,2}$, Michael I. Polkey ${ }^{3}$ and Nicholas S. Hopkinson ${ }^{3}$
}

Affiliations: 'Dept of Palliative Care, Policy and Rehabilitation, King's College London, London, UK. ${ }^{2}$ Dept of Asthma, Allergy and Lung Biology, King's College London, London, UK. ${ }^{3}$ National Heart and Lung Institute, NIHR Respiratory Biomedical Research Unit, Royal Brompton and Harefield NHS Foundation Trust and Imperial College, London, UK. 'NIHR Comprehensive Biomedical Research Centre, Guy's and St Thomas' NHS Foundation Trust and King's College London, London, UK. ${ }^{5}$ Both authors contributed equally.

Correspondence: Nicholas S. Hopkinson, National Heart and Lung Institute, Royal Brompton Hospital, Fulham Road, London, SW3 6NP, UK. E-mail: n.hopkinsondic.ac.uk

ABSTRACT Quadriceps muscle phenotype varies widely between patients with chronic obstructive pulmonary disease (COPD) and cannot be determined without muscle biopsy. We hypothesised that measures of skeletal muscle adiposity could provide noninvasive biomarkers of muscle quality in this population.

In 101 patients and 10 age-matched healthy controls, mid-thigh cross-sectional area, percentage intramuscular fat and skeletal muscle attenuation were calculated using computed tomography images and standard tissue attenuation ranges: fat -190- -30 HU; skeletal muscle -29-150 HU.

Mean \pm SD percentage intramuscular fat was higher in the patient group $(6.7 \pm 3.5 \%$ versus $4.3 \pm 1.2 \%$, $\mathrm{p}=0.03$ ). Both percentage intramuscular fat and skeletal muscle attenuation were associated with physical activity level, exercise capacity and type I fibre proportion, independent of age, mid-thigh cross-sectional area and quadriceps strength. Combined with transfer factor of the lung for carbon monoxide, these variables could identify $>80 \%$ of patients with fibre type shift with $>65 \%$ specificity (area under the curve $0.83,95 \%$ CI $0.72-0.95)$.

Skeletal muscle adiposity assessed by computed tomography reflects multiple aspects of COPD related muscle dysfunction and may help to identify patients for trials of interventions targeted at specific muscle phenotypes.

@ERSpublications

CT-based skeletal muscle adiposity markers reflect muscle quality in COPD and help identify patients with fibre shift http://ow.ly/xolWA

\section{This article has supplementary material available from erj.ersjournals.com}

Received: Jan 082014 | Accepted after revision: May 232014 | First published online: July 032014

Support statement: M. Maddocks is a National Institute for Health Research (NIHR) Post-Doctoral Research Fellow. N.S. Hopkinson is a Higher Education Funding Council for England (HEFCE) Clinical Senior Lecturer. The study was supported by the NIHR Respiratory Biomedical Research Unit of the Royal Brompton and Harefield NHS Foundation Trust, and Imperial College London who part fund M.I. Polkey's salary. The views expressed in this publication are those of the authors and not necessarily those of the NHS, the NIHR or the Department of Health.

Conflict of interest: None declared.

Copyright OERS 2014. ERJ Open articles are open access and distributed under the terms of the Creative Commons Attribution Non-Commercial Licence 4.0. 


\section{Introduction}

Skeletal muscle dysfunction is an important complication of chronic obstructive pulmonary disease (COPD) occurring in mild as well as more advanced disease $[1,2]$. It is largely driven by physical inactivity and is most apparent in muscles of the lower limb, in particular the quadriceps [3,4]. Quadriceps weakness is associated with reduced exercise performance [5], poor health status [6], increased healthcare utilisation [7] and mortality, independent of airflow obstruction [8]. Changes in the quadriceps include muscle atrophy, loss of strength and endurance $[9,10]$, and a shift towards a less aerobic phenotype with reduced type I fibre proportions, capillarity and oxidative enzymes [11, 12]. The degree and nature of impairment varies widely between patients and cannot currently be predicted accurately without muscle biopsy [13]. The need for biomarkers of muscle phenotype has recently been highlighted, underscored by the prospect of new pharmacotherapies that selectively target certain muscle characteristics [14]. For example, peroxisome proliferator-activated receptor- $\delta$ agonists or 5' AMP-activated protein kinase activators, which change the fuel preference within skeletal muscle away from glycolysis towards fat oxidation.

Computed tomography (CT) is an established method to assess muscle mass or quantity [15]. Images can also be analysed to assess muscle quality by the level of fatty infiltration of muscle, or muscle adiposity. Skeletal muscle adiposity increases with age [16] and, independent of mass, is associated with muscle triglyceride content [17], oxidative capacity [18], insulin resistance [19], muscle strength and power [20, 21], as well as immobility and hip fracture $[22,23]$. Little is known about muscle adiposity in patients with COPD, but given the above, we predicted that CT-based measures could be valuable biomarkers of muscle phenotype in this group. In particular, their use may help identify patients with type I to type II muscle fibre shift as candidates for trials of targeted therapies. In this study, we hypothesised that mid-thigh intramuscular fat and muscle attenuation would be associated with physical activity, exercise capacity and fibre shift.

\section{Methods \\ Study design and subjects}

Data were collated from patients with a diagnosis of COPD consistent with the Global Initiative for Chronic Obstructive Lung Disease (GOLD) criteria [24] who had previously participated in two clinical studies at the Royal Brompton, King's College or St Thomas' Hospitals (London, UK). Some of the phenotypic data for some of these patients has been previously reported $[6,25]$. Exclusion criteria were: diagnoses of heart, renal or liver failure; systemic inflammatory, metabolic or neuromuscular disorders; warfarin (bleeding risk from biopsy); or an exacerbation within the preceding 4 weeks. Healthy age-matched controls with no history or symptoms of respiratory or cardiovascular disease, or unresolved musculoskeletal injury were recruited by local advertisement. All participants had provided written informed consent for studies approved by the Joint University College London Committees on the Ethics of Human Research (Committee Alpha) and the Ethics Committee of the Royal Brompton and Harefield NHS Foundation Trust.

\section{Mid-thigh composition}

CT was performed on a 64-slice CT scanner (SOMATOM Sensation 64; Siemens, Erlangen, Germany) with the patient in a supine position. A single section of both mid-thighs, at a predefined level, was obtained using the following acquisition parameters: $50 \mathrm{~mA} \cdot \mathrm{s}$ and $120 \mathrm{kVp}$. The protocol was modified to deliver a reduced amount of radiation per scan. Images were viewed and analysed using SliceOMatic software (version 4.3; TomoVision, Magog, QC, Canada).

Skeletal muscle and intramuscular fat were identified and quantified by use of standard Hounsfield unit thresholds, which represent the physical properties of tissues expressed in numerical form (skeletal muscle -29-150 HU; intramuscular fat -190--30 HU) [26]. By specifying Hounsfield unit range, the software filters by tissue type and allows each to be quantified in turn. Tissue perimeters can be altered manually where necessary (fig. 1). Intramuscular fat was normalised to mid-thigh cross-sectional area (MTCSA) and expressed as a percentage. Skeletal muscle attenuation was measured using the mean radiation attenuation in Hounsfield units, which reflects macroscopic fatty muscle infiltration. A lower mean indicates less attenuation and greater fat infiltration. These methods are highly reliable with reported intra- and interclass coefficients of variation between $0.2 \%$ and $4.8 \%[27,28]$.

\section{Additional measurements}

Lung volumes, transfer factor of the lung for carbon monoxide (TLCO), fat mass and fat free mass index (FFMI), daily step count and physical activity level (PAL), quadriceps maximum voluntary contraction (QMVC) and twitch tension, vastus lateralis fibre type and shift, exercise capacity as assessed by incremental shuttle walk test (ISWT) or 6-min walking distance (6MWD), and health-related quality of life were assessed as described previously $[6,25]$ and in the online supplementary material. 


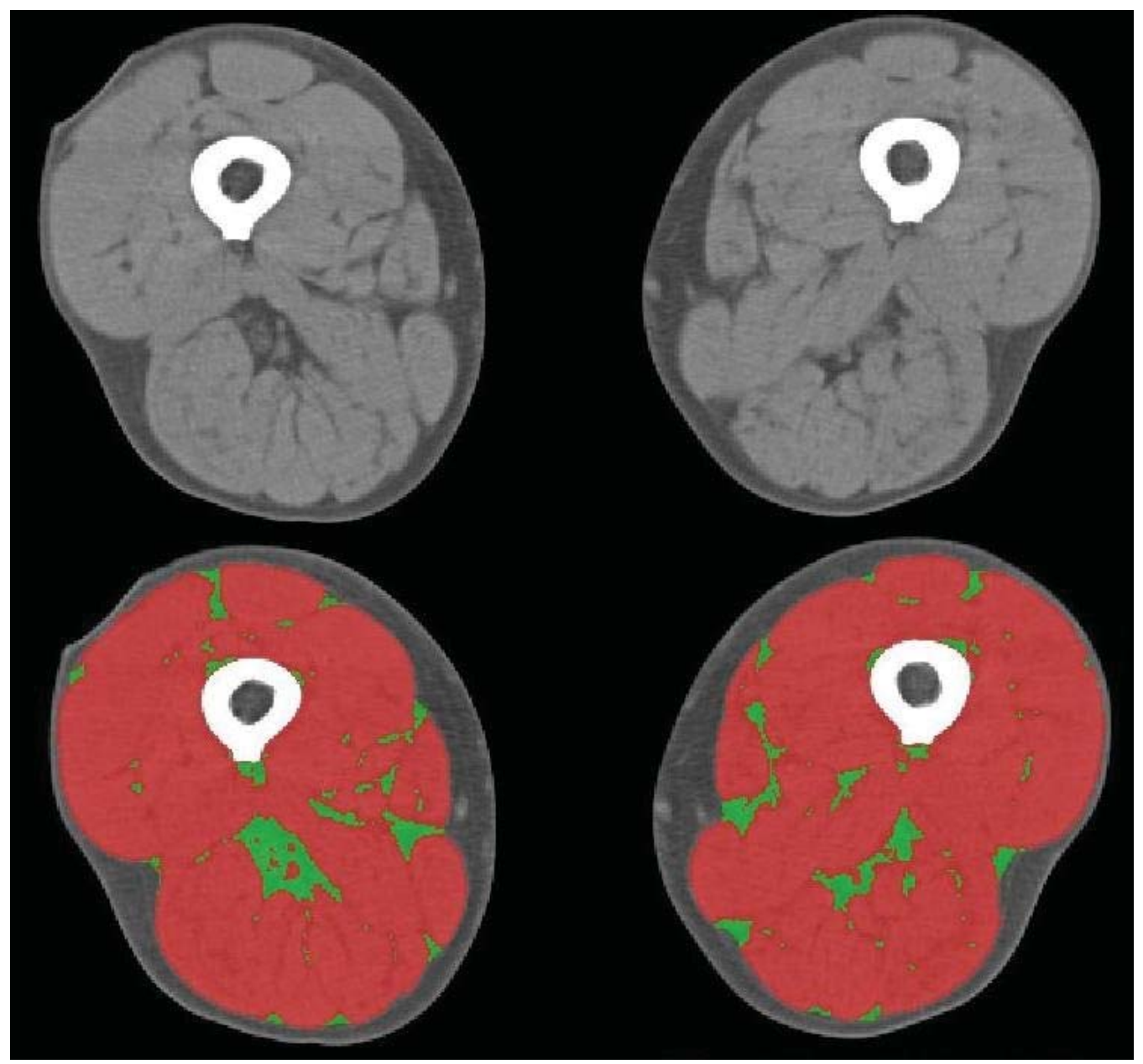

FIGURE 1 Mid-thigh compositional analysis based on a single slice computed tomography image. Tissues were differentiated according to standardised Hounsfield unit thresholds; skeletal muscle (red) -29-150 HU, adipose tissue (green) $-190--30 \mathrm{HU}$.

\section{Statistical analysis}

Normally distributed continuous data are presented as mean \pm SD. Between-group comparisons were performed using unpaired t-test, Chi-squared tests or one-way ANOVA, as appropriate. Associations between measures of skeletal muscle adiposity and other variables were analysed using Pearson's correlation coefficients, and univariate and multivariate linear regression models incorporating age, MTCSA, QMVC and TLCO \% predicted as independent variables. For receiver operating characteristic (ROC) analysis, percentage intramuscular fat and skeletal muscle attenuation were used alone or in combination to discriminate subjects according to the presence of fibre shift. Statistical analysis and graphical presentations were performed using SPSS version 19 (IBM Corp., Armonk, NY, USA) and GraphPad Prism 5 (GraphPad Software Inc., San Diago, CA, USA), respectively. No attempt at imputation of missing data was made. A p-value of $<0.05$ was regarded as statistically significant.

\section{Results}

\section{Subjects}

CT data were available for 111 subjects: 101 COPD patients and 10 healthy age-matched controls (table 1). Consistent with a diagnosis of COPD, patients had impaired lung function and reduced arterial blood oxygen tension compared with controls. There were no significant differences in age, body mass index, FFMI or arterial blood carbon dioxide tension between the patient and healthy control groups, but patients had significantly reduced quadriceps strength, and mid-thigh and lean tissue cross-sectional area (table 1).

Percentage intramuscular fat was significantly elevated in patients with COPD compared with healthy controls, with mean $\pm \mathrm{SD}$ values of $6.6 \pm 3.3 \%$ and $4.3 \pm 1.2 \%$, respectively $(\mathrm{p}=0.03)$. In the patient group, 
TABLE 1 Subject characteristics

\begin{tabular}{|c|c|c|c|}
\hline & Healthy & COPD & p-value \\
\hline Subjects & 10 & 101 & \\
\hline Males/females & $4 / 6$ & $60 / 41$ & 0.20 \\
\hline Age years & $68.0 \pm 7.3$ & $64.8 \pm 7.6$ & 0.21 \\
\hline Height $\mathrm{cm}$ & $166 \pm 9$ & $169 \pm 9$ & 0.42 \\
\hline Weight $\mathbf{k g}$ & $75.8 \pm 14.6$ & $70.0 \pm 15.1$ & 0.25 \\
\hline Body mass index $\mathrm{kg} \cdot \mathrm{m}^{-2}$ & $27.2 \pm 3.7$ & $24.5 \pm 4.8$ & 0.09 \\
\hline Fat mass $\mathrm{kg}$ & $22.4 \pm 9.7$ & $27.0 \pm 6.0$ & 0.15 \\
\hline Fat-free mass kg & $48.8 \pm 12.1$ & $47.7 \pm 9.0$ & 0.71 \\
\hline Fat-free mass index $\mathrm{kg} \cdot \mathrm{m}^{-2}$ & $16.9 \pm 2.7$ & $16.8 \pm 2.4$ & 0.85 \\
\hline Current/former/never-smoker & $1 / \overline{4} / 5$ & $25 / 76 / 0$ & $<0.01$ \\
\hline Smoking pack-years & $10 \pm 15$ & $49 \pm 24$ & $<0.01$ \\
\hline FEV1 L & $2.59 \pm 0.64$ & $1.08 \pm 0.54$ & $<0.01$ \\
\hline FEV1 \% predicted & $106 \pm 13$ & $41 \pm 20$ & $<0.01$ \\
\hline VC L & $3.72 \pm 0.95$ & $3.00 \pm 0.79$ & $<0.01$ \\
\hline VC \% predicted & $121 \pm 19$ & $89 \pm 19$ & $<0.01$ \\
\hline FEV $1 /$ VC & $69.9 \pm 5.7$ & $35.8 \pm 13.8$ & $<0.01$ \\
\hline TLC L & $5.97 \pm 1.32$ & $7.34 \pm 1.74$ & 0.02 \\
\hline TLC $\%$ predicted & $105 \pm 11$ & $123 \pm 19$ & $<0.01$ \\
\hline RV L & $2.31 \pm 0.55$ & $4.26 \pm 1.49$ & $<0.01$ \\
\hline RV \% predicted & $102 \pm 12$ & $189 \pm 60$ & $<0.01$ \\
\hline $\mathrm{RV} / \mathrm{TLC}$ & $39 \pm 6$ & $56 \pm 12$ & $<0.01$ \\
\hline TLCO L & $6.79 \pm 1.52$ & $3.49 \pm 1.58$ & $<0.01$ \\
\hline TLco $\%$ predicted & $87 \pm 13$ & $42 \pm 19$ & $<0.01$ \\
\hline $\mathrm{PCO}_{2} \mathrm{kPa}$ & $5.34 \pm 0.47$ & $5.20 \pm 0.70$ & 0.55 \\
\hline $\begin{array}{l}\mathrm{PO}_{2} \mathrm{kPa} \\
\mathrm{GOLD} \text { staqe } \mathrm{I} / \mathrm{II} / \mathrm{II} / \mathrm{IV}\end{array}$ & $11.28 \pm 1.02$ & $\begin{array}{l}9.61 \pm 1.53 \\
4 / 26 / 31 / 40\end{array}$ & $<0.01$ \\
\hline GOLD grade $A / B / C / D$ & & $9 / 4 / 19 / 69$ & \\
\hline Exacerbations in the past year & & $1(0-2)$ & \\
\hline \multicolumn{4}{|l|}{ Medication n (\%) } \\
\hline Long-acting $\beta$-agonist & & $85(84)$ & \\
\hline Inhaled corticosteroid & & $85(84)$ & \\
\hline Oral steroid $>5 \mathrm{mg} \cdot$ day $^{-1}$ & & $8(8)$ & \\
\hline Oxygen & & $18(18)$ & \\
\hline Nocturnal NIV & & $8(8)$ & \\
\hline SGRQ & $8.2 \pm 9.9$ & $49.9 \pm 19.0$ & $<0.01$ \\
\hline QMVC kg & $31.5 \pm 9.2$ & $26.7 \pm 7.4$ & 0.05 \\
\hline $\begin{array}{l}\text { Quadriceps twitch force kg } \\
\text { Body composition (both thighs) }\end{array}$ & $7.4 \pm 2.1$ & $9.7 \pm 3.1$ & 0.04 \\
\hline MTCSA $\mathrm{cm}^{2}$ & $221.8 \pm 44.9$ & $190.9 \pm 47.6$ & 0.04 \\
\hline Lean tissue cross-sectional area $\mathrm{cm}^{2}$ & $212.1 \pm 42.5$ & $178.0 \pm 44.4$ & 0.02 \\
\hline Lean tissue $\mathrm{HU}$ & $42.3 \pm 4.0$ & $41.5 \pm 4.8$ & 0.63 \\
\hline Intramuscular fat $\mathrm{cm}^{2}$ & $11.8 \pm 5.1$ & $13.0 \pm 7.4$ & 0.64 \\
\hline Intramuscular fat \% & $4.30 \pm 1.23$ & $6.64 \pm 3.32$ & 0.03 \\
\hline \multicolumn{4}{|l|}{ Fibre type $\%^{\#}$} \\
\hline I & $48.9 \pm 9.7$ & $28.2 \pm 12.5$ & $<0.01$ \\
\hline Ila & $44.3 \pm 8.5$ & $57.0 \pm 13.4$ & 0.01 \\
\hline$\| x$ & $3.2 \pm 4.6$ & $12.1 \pm 13.1$ & 0.02 \\
\hline II & $47.5 \pm 10.1$ & $67.9 \pm 15.2$ & $<0.01$ \\
\hline \multicolumn{4}{|l|}{ Exercise capacity ${ }^{\#}$} \\
\hline $6 \mathrm{MWD} \mathrm{m}$ & $572 \pm 81$ & $341 \pm 141$ & $<0.01$ \\
\hline ISWT m & & $250 \pm 132$ & \\
\hline \multicolumn{4}{|l|}{ Physical activity } \\
\hline Wear time h per day & & $23.6 \pm 0.5$ & \\
\hline Wear time $\%$ & & $98.3 \pm 0.2$ & \\
\hline TEE kcal per day & & $1976 \pm 332$ & \\
\hline Steps per day & & $4501 \pm 3273$ & \\
\hline PAL & & $1.41 \pm 0.17$ & \\
\hline
\end{tabular}

Data are presented as $n$, mean \pm SD or median (interquartile range), unless otherwise stated. COPD: chronic obstructive pulmonary disease; FEV1: forced expiratory volume in $1 \mathrm{~s}$; VC: vital capacity; TLC: total lung capacity; RV: residual volume; TLCo: transfer factor of the lung for carbon monoxide; $\mathrm{PCO}_{2}$ : carbon dioxide tension; $\mathrm{PO}_{2}$ : oxygen tension; GOLD: Global Initiative for Chronic Obstructive Lung Disease; NIV: noninvasive ventilation; SGRQ: St George's respiratory questionnaire; QMVC: quadriceps maximum voluntary contraction; MTCSA: mid-thigh cross-sectional area; 6MWD: 6-min walking distance; ISWT: incremental shuttle walk test; TEE: total energy expenditure; PAL: physical activity level. * : COPD fibre type $n=48$, ISWT $n=30,6 M W D$ and physical activity $n=69$. 
values stratified by GOLD stage revealed that fat infiltration tended to be greater in those with advanced disease, although the between group differences were not significant (GOLD I/II/III/IV 5.0 $\pm 0.5 / 5.9 \pm 0.5$ / $7.9 \pm 0.7 / 6.4 \pm 0.5 \%$ ) (table 1). Skeletal muscle attenuation was numerically, but not significantly, different between patient and control groups (table 1), and was significantly reduced in the patients with most fat infiltration (table 2).

\section{Reproducibility}

For all measures based on a standard CT image, the mean differences between two researchers, or repeat assessments by the same researcher were less than $1 \%$ of the mean value for both assessments. The lower 95\% confidence intervals of correlation coefficients for all assessments exceeded 0.99 and can be interpreted as excellent (tables S1a and S1b). A subset of 29 patients had an additional CT scan following 3 months participation in the placebo arm of a clinical trial. Overall, repeat assessments demonstrated good reproducibility with all lower 95\% confidence intervals of correlation coefficients exceeding 0.70 (table S1c).

\section{Skeletal muscle adiposity and physical activity}

Percentage intramuscular fat was negatively correlated with step count $(r=-0.27, p=0.03)$ and PAL $(\mathrm{r}=-0.35, \mathrm{p}=0.003)$ (fig. 2), although only PAL was significantly reduced in patients in the upper compared with the lower quartile of this measure $(\mathrm{p}=0.04)$ (table 2$)$. In a regression model, percentage intramuscular fat was significantly associated with step count $(\beta$ coefficient \pm SE $-258 \pm 121, p=0.04)$ and PAL $(\beta \pm$ SE $-0.02 \pm 0.01, p=0.007)$ independent of age, MTCSA and QMVC, but not TLCO \% pred.

Skeletal muscle attenuation was positively correlated with step count $(r=0.36, p=0.003)$ and PAL $(\mathrm{r}=0.35, \mathrm{p}=0.004)$ (fig. 2) and was significantly associated with these variables independent of age, MTCSA and QMVC, but not TLCO \% pred (step count $\beta \pm$ SE $206 \pm 100, p=0.02$; PAL $\beta \pm$ SE $0.13 \pm 0.01, p=0.008$ ).

\section{Skeletal muscle adiposity and exercise capacity}

Percentage intramuscular fat was negatively correlated with ISWT ( $\mathrm{r}=-0.45, \mathrm{p}<0.001)$, and 6MWD when analysed with $(\mathrm{r}=-0.49, \mathrm{p}=0.001)$ and without $(\mathrm{r}=-0.42, \mathrm{p}=0.02)$ control subjects (fig. 3$)$. ISWT and $6 \mathrm{MWD}$ were significantly reduced among patients in the upper quartile of percentage intramuscular fat compared with those in the lower quartile (table 2). Percentage intramuscular fat was significantly associated with ISWT $(\beta \pm \mathrm{SE}-16.0 \pm 4.5, \mathrm{p}<0.001)$ and $6 \mathrm{MWD}(\beta \pm \mathrm{SE}-19.5 \pm 6.2, \mathrm{p}=0.004)$ independent of age, MTCSA, QMVC and TLCO \% pred.

Skeletal muscle attenuation was positively correlated with ISWT distance $(r=0.37, p=0.002)$ and 6 MWD when analysed with $(\mathrm{r}=0.57, \mathrm{p}=0.001)$ or without $(\mathrm{r}=0.60, \mathrm{p}=0.001)$ control subjects (fig. 3$)$, and was significantly associated with exercise performance independent of age, MTCSA, QMVC and TLCO \% pred (ISWT $\beta \pm$ SE 9.8 $\pm 3.8, \mathrm{p}=0.001 ; 6 \mathrm{MWD} \beta \pm$ SE $12.7 \pm 3.8, \mathrm{p}=0.002$ ).

\section{Skeletal muscle adiposity and fibre shift}

Percentage intramuscular fat was negatively correlated with the percentage of type I fibres when analysed with $(r=-0.36, p=0.006)$ and without $(r=-0.27, p=0.05)$ control subjects (fig. S1). Percentage of type I fibres was not significantly different between patients in the upper and lower quartile of percentage intramuscular fat, but percentage of type IIx fibres was significantly greater in patients with most fat infiltration $(21.8 \pm 18.4 \%$ versus $8.4 \pm 8.7 \%, \mathrm{p}=0.04)$. Percentage intramuscular fat was independently associated with percentage of type I fibres when considered with age, MTCSA and QMVC, but not TLCO \% pred $(\beta \pm \mathrm{SE}-1.3 \pm 0.6, \mathrm{p}=0.04)$. In a similar analysis, skeletal muscle attenuation was positively correlated with percentage of type I fibres $(r=0.30, p=0.02)$ (fig. $S 1 b)$ but was not independently associated when the other factors were considered.

To determine whether measures of skeletal muscle adiposity could predict fibre shift, a ROC analysis was performed with fibre shift, defined as percentage of type I fibres $\leqslant 27 \%$, as the dependent variable. TLCO $\%$ pred was a stronger predictor of fibre shift than percentage intramuscular fat and skeletal muscle attenuation, with area under the curve (AUC) values (95\% CI) of $0.825(0.709-0.940)$ and $0.648(0.7494-0.802)$, respectively (fig. 4). Combining measures of skeletal muscle adiposity with TLCO \% pred, the AUC increased to 0.833 (fig. 4). The curve profile also changed such that, with a greater emphasis on sensitivity than specificity, measures of skeletal muscle adiposity could be used with TLCO $\%$ pred to identify $>80 \%$ of patients with fibre shift with $>65 \%$ specificity (fig. 4 ).

\section{Skeletal muscle adiposity and COPD characteristics}

Neither percentage intramuscular fat nor skeletal muscle attenuation were significantly associated with sex, body mass index, FFMI, MTCSA or QMVC. The latter measures were not as consistently related to physical activity, exercise capacity or fibre shift as measures of skeletal muscle adiposity (table S2). Percentage 
TABLE 2 Clinical characteristics of chronic obstructive pulmonary disease patients stratified by upper and lower quartile of percentage intramuscular fat

\begin{tabular}{|c|c|c|c|}
\hline & Lower quartile & Upper quartile & p-value \\
\hline Subjects & 25 & 25 & \\
\hline Males/females & $17 / 8$ & $15 / 10$ & 0.38 \\
\hline Age years & $63.4 \pm 7.3$ & $66.4 \pm 6.3$ & 0.14 \\
\hline Height $\mathrm{cm}$ & $169 \pm 8$ & $168.2 \pm 8.7$ & 0.60 \\
\hline Weight kg & $63.9 \pm 15.2$ & $75.9 \pm 15.5$ & 0.01 \\
\hline Body mass index $\mathrm{kg} \cdot \mathrm{m}^{-2}$ & $22.0 \pm 4.2$ & $26.7 \pm 5.2$ & 0.001 \\
\hline Fat mass kg & $16.1 \pm 6.4$ & $26.0 \pm 9.5$ & 0.001 \\
\hline Fat-free mass kg & $47.7 \pm 10.5$ & $49.8 \pm 8.0$ & 0.43 \\
\hline Fat-free mass index $\mathrm{kg} \cdot \mathrm{m}^{-2}$ & $16.7 \pm 2.6$ & $17.1 \pm 2.6$ & 0.61 \\
\hline Smoking pack-years & $49 \pm 19$ & $57 \pm 29$ & 0.32 \\
\hline FEV1 L & $1.16 \pm 0.62$ & $0.98 \pm 0.43$ & 0.25 \\
\hline FEV $1 \%$ predicted & $42 \pm 21$ & $37 \pm 15$ & 0.42 \\
\hline VC L & $3.37 \pm 0.84$ & $2.83 \pm 0.85$ & 0.03 \\
\hline VC \% predicted & $94 \pm 18$ & $85 \pm 17$ & 0.08 \\
\hline $\mathrm{FEV}_{1} / \mathrm{VC}$ & $32.6 \pm 13.4$ & $35.2 \pm 11.8$ & 0.49 \\
\hline TLC L & $7.98 \pm 1.5$ & $6.97 \pm 1.73$ & 0.04 \\
\hline TLC \% predicted & $129 \pm 14$ & $116 \pm 16$ & 0.005 \\
\hline RV L & $4.54 \pm 1.25$ & $4.09 \pm 1.17$ & 0.21 \\
\hline RV \% predicted & $201 \pm 58$ & $179 \pm 42$ & 0.14 \\
\hline RV/TLC & $52 \pm 15$ & $59 \pm 7$ & 0.08 \\
\hline TLCO L & $3.66 \pm 1.72$ & $2.98 \pm 1.49$ & 0.18 \\
\hline TLCO $\%$ predicted & $42 \pm 18$ & $37 \pm 18$ & 0.35 \\
\hline $\mathrm{PCO}_{2} \mathrm{kPa}$ & $5.21 \pm 0.43$ & $5.27 \pm 0.92$ & 0.76 \\
\hline $\mathrm{PO}_{2} \mathrm{kPa}$ & $10.25 \pm 1.38$ & $9.11 \pm 1.72$ & 0.02 \\
\hline GOLD stage I/II/III/IV & $1 / 7 / 6 / 11$ & $0 / 5 / 13 / 7$ & 0.19 \\
\hline GOLD grade $A / B / C / D$ & $2 / 2 / 3 / 18$ & $1 / 0 / 2 / 17$ & 0.27 \\
\hline \multicolumn{4}{|l|}{ Medication n $(\%)$} \\
\hline Long-acting $\beta$-agonist & $21(84)$ & $22(88)$ & 0.46 \\
\hline Inhaled corticosteroid & $21(84)$ & $22(88)$ & 0.20 \\
\hline Oral steroid $>5 \mathrm{mg} \cdot$ day $^{-1}$ & $3(12)$ & 2 (8) & 0.50 \\
\hline Oxygen & $4(16)$ & $8(32)$ & 0.16 \\
\hline Nocturnal NIV & $0(0)$ & $4(16)$ & 0.03 \\
\hline SGRQ & $47.2 \pm 21.2$ & $56.5 \pm 13.5$ & 0.09 \\
\hline QMVC kg & $25.4 \pm 8.2$ & $26.1 \pm 7.6$ & 0.76 \\
\hline $\begin{array}{l}\text { Quadriceps twitch force } \mathrm{kg} \\
\text { Body composition (both thighs) }\end{array}$ & $10.3 \pm 3.0$ & $9.0 \pm 2.7$ & 0.21 \\
\hline MTCSA $\mathrm{cm}^{2}$ & $190.9 \pm 49.2$ & $188.2 \pm 50.4$ & 0.85 \\
\hline Lean tissue cross-sectional area $\mathrm{cm}^{2}$ & $185.0 \pm 48.4$ & $167.1 \pm 45.0$ & 0.19 \\
\hline Lean tissue HU & $44.9 \pm 4.7$ & $37.6 \pm 4.9$ & $<0.001$ \\
\hline Intramuscular fat $\mathrm{cm}^{2}$ & $5.8 \pm 2.1$ & $21.1 \pm 7.1$ & $<0.001$ \\
\hline Intramuscular fat \% & $2.94 \pm 0.80$ & $11.22 \pm 2.20$ & $<0.001$ \\
\hline \multicolumn{4}{|l|}{ Fibre type $\%^{\#}$} \\
\hline I & $29.3 \pm 13.3$ & $21.8 \pm 10.5$ & 0.14 \\
\hline Ila & $60.9 \pm 16.3$ & $59.3 \pm 11.6$ & 0.79 \\
\hline$\| x$ & $8.4 \pm 8.7$ & $21.0 \pm 18.4$ & 0.04 \\
\hline II & $69.3 \pm 14.1$ & $76.8 \pm 11.4$ & 0.68 \\
\hline \multicolumn{4}{|l|}{ Exercise capacity ${ }^{\#}$} \\
\hline 6MWD m & $404 \pm 166$ & $188 \pm 83$ & 0.03 \\
\hline ISWT m & $295 \pm 138$ & $172 \pm 88$ & 0.003 \\
\hline \multicolumn{4}{|l|}{ Physical activity\# } \\
\hline Wear time h per day & $23.7 \pm 0.4$ & $23.7 \pm 0.3$ & 0.87 \\
\hline Wear time $\%$ & $98.7 \pm 1.6$ & $98.8 \pm 1.1$ & 0.81 \\
\hline TEE kcal per day & $1961 \pm 412$ & $1925 \pm 296$ & 0.76 \\
\hline Steps per day & $4632 \pm 3407$ & $3073 \pm 2167$ & 0.11 \\
\hline PAL & $1.44 \pm 0.17$ & $1.33 \pm 0.12$ & 0.04 \\
\hline
\end{tabular}

Data are presented as $\mathrm{n}$, mean \pm SD or median (interquartile range), unless otherwise stated. FEV1: forced expiratory volume in $1 \mathrm{~s}$; VC: vital capacity; TLC: total lung capacity; RV: residual volume; TLCO: transfer factor of the lung for carbon monoxide; $P \mathrm{CO}_{2}$ : carbon dioxide tension; $\mathrm{PO}_{2}$ : oxygen tension; GOLD: Global Initiative for Chronic Obstructive Lung Disease; NIV: noninvasive ventilation; SGRQ: St George's respiratory questionnaire; QMVC: quadriceps maximum voluntary contraction; MTCSA: mid-thigh cross-sectional area; 6MWD: 6-min walking distance; ISWT: incremental shuttle walk test; TEE: total energy expenditure; PAL: physical activity level. ${ }^{\#}$ : comparison limited to $n=14$ versus $n=11$ for fibre type, $n=6$ versus $n=5$ for 6 MWD and $n=19$ versus $n=18$ for ISWT and physical activity measures.

intramuscular fat was not significantly associated with the other characteristics assessed except for fat mass $(\mathrm{r}=0.38, \mathrm{p}<0.001)$. Skeletal muscle attenuation was associated with age $(\mathrm{r}=-0.30, \mathrm{p}=0.002)$, TLCO \% pred $(\mathrm{r}=0.30, \mathrm{p}=0.003)$, quadriceps twitch force $(\mathrm{r}=0.37, \mathrm{p}=0.01)$, MTCSA $(\mathrm{r}=0.22, \mathrm{p}=0.02)$ and fat mass $(\mathrm{r}=-0.19, \mathrm{p}=0.04)$. 

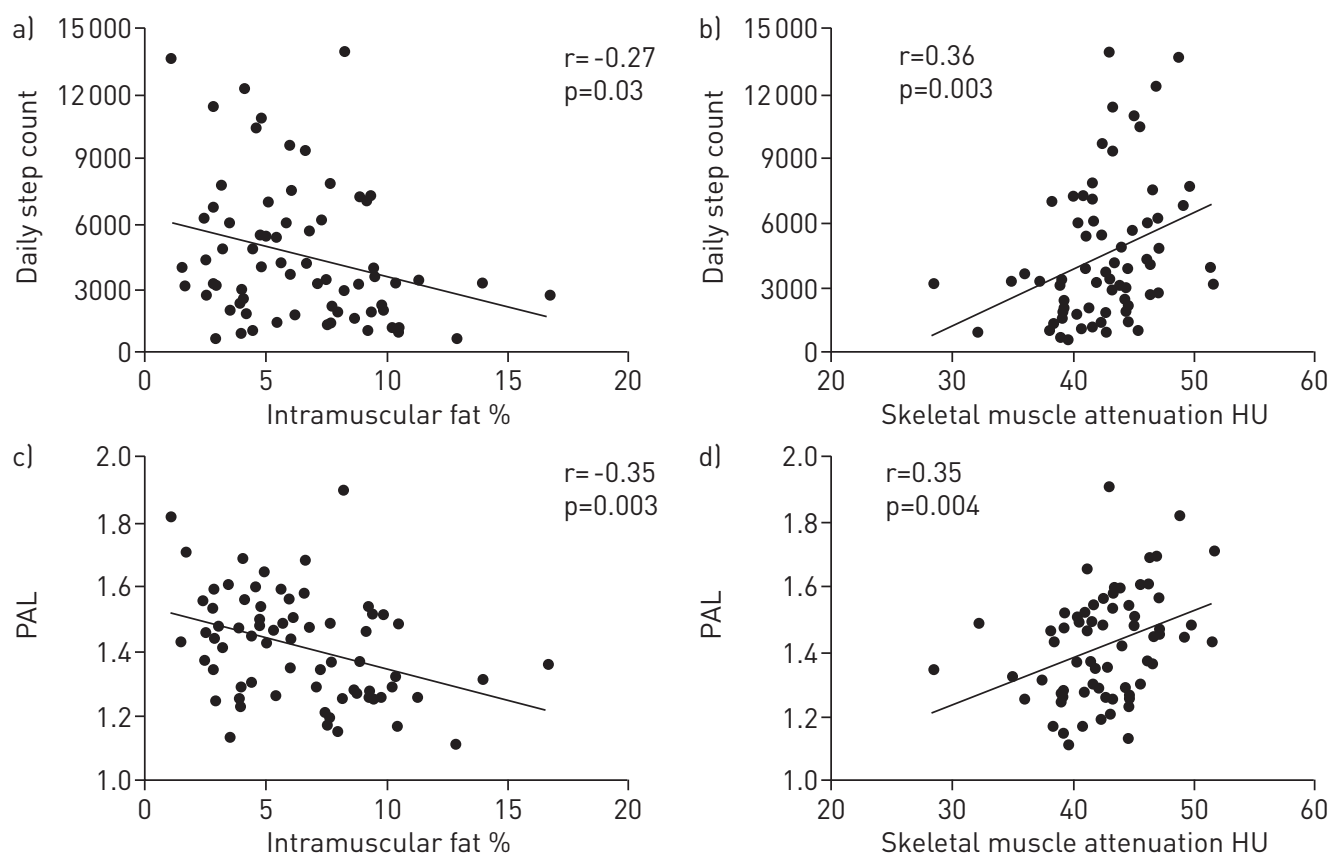

FIGURE 2 Relationship between a, c) mid-thigh percentage intramuscular fat and b, d) skeletal muscle attenuation and physical inactivity as assessed by a, b) mean daily step count and c, d) physical activity level (PAL).

\section{Discussion}

We have investigated CT-based measures of skeletal muscle adiposity in patients with COPD. Patients had a significantly elevated percentage of intramuscular fat compared with age-matched healthy controls. Moderate significant associations were found between percentage intramuscular fat and skeletal muscle attenuation, and measures of physical activity, exercise capacity and muscle fibre type independent of age, quadriceps strength and MTCSA. By combining measures of skeletal muscle adiposity with TLCO, $>80 \%$ of subjects with quadriceps fibre shift could be identified with $>65 \%$ specificity.

\section{Significance of the findings}

Our findings extend knowledge regarding the extent and nature of quadriceps muscle dysfunction in COPD. Reductions in muscle mass, strength and endurance are well known phenomena, as are fibre shift and loss of oxidative capacity [8, 9, 13]. Abnormally high levels of lipids have also been observed microscopically in the quadriceps of patients with COPD both under the fascia [29] and within muscle fibres $[30,31]$.

Image-based measures of quadriceps muscle structure may help to identify patients with specific muscle phenotypes. Muscle biopsy data confirm that COPD muscle abnormalities are heterogeneous, unrelated to muscle strength and that, on average, only $50 \%$ of unselected patients will have pathological fibre shift or fibre atrophy [13]. For emerging pharmacotherapies that have fibre-type specific modes of action, such as those that affect the transcriptional coactivator [32] or stimulate fatty acid oxidation [33], practical biomarkers to identify relevant populations for study are desirable. Other biomarkers have been suggested for this purpose, including ${ }^{31} \mathrm{P}$-magnetic resonance spectroscopy (MRS) [34] and plasma microRNA-1 [35]. CT measures are less expensive to undertake than ${ }^{31} \mathrm{P}-\mathrm{MRS}$, and are likely to be more rapidly available and more stable than any biomarker based on blood analysis.

Our findings also support data suggesting that emphysema (evaluated here via TLCO) rather than airflow obstruction is the more closely associated with skeletal muscle abnormalities [36] and strength [37] than FEV1, although in this it differs from the review by GOSKER et al. [11], which found FEV1 was more strongly associated than TLCO at the study level. For study stratification, CT has the advantage that it can be scored centrally and is less patient- and operator-dependent than gas transfer measurement.

The accumulation of fat in the skeletal muscle of patients with COPD may reflect an intermediate between a type I to type II fibre shift and insulin resistance. Oxidative muscle fibres consume fats [38] and these results are consistent with the observation that transgenic animal models with an increased skeletal muscle oxidative fibre proportion have a reduced intramuscular triglyceride content, compared to wild-type 

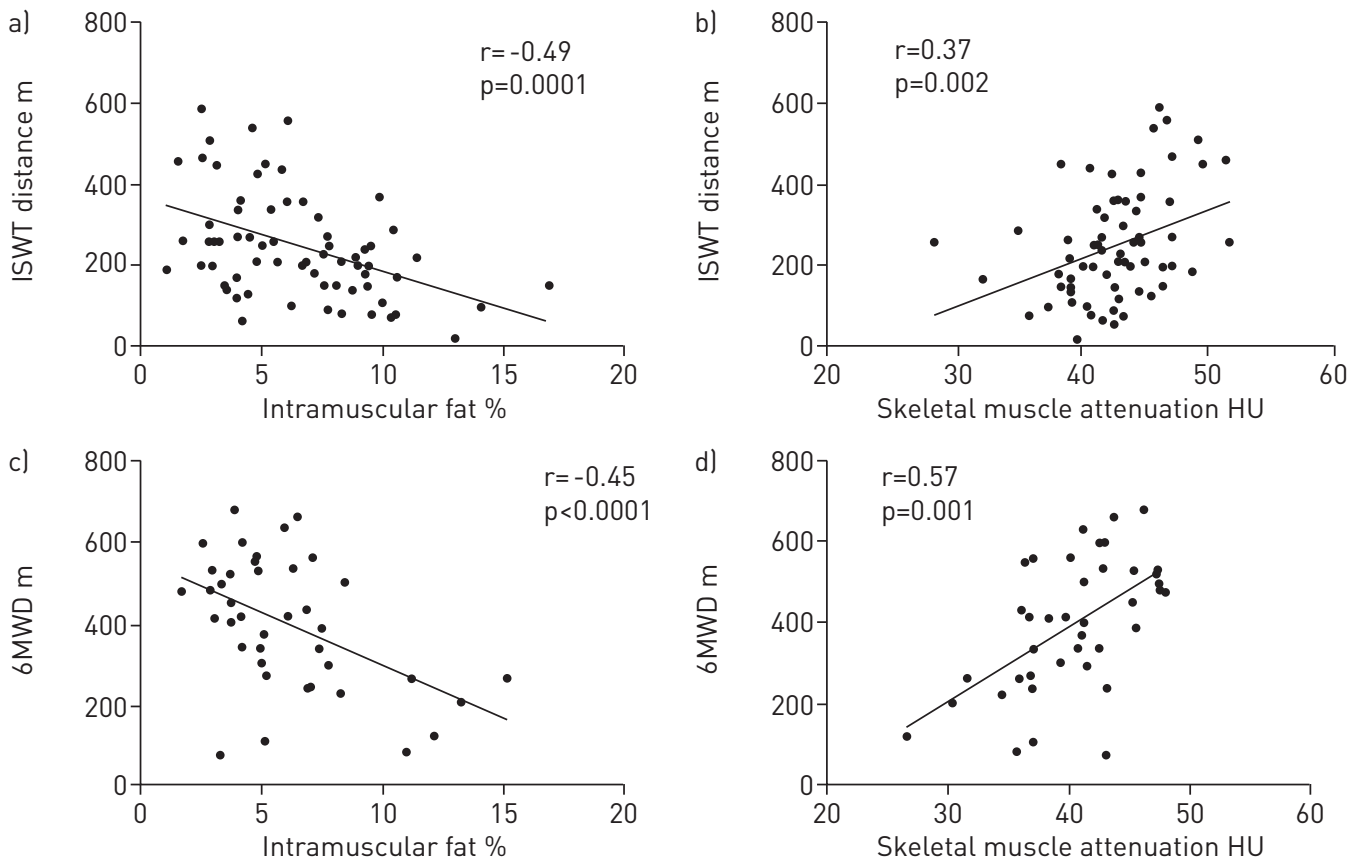

FIGURE 3 Relationship between a, c) mid-thigh percentage intramuscular fat and b, d) skeletal muscle attenuation and exercise capacity as assessed by the a, b) incremental shuttle walk test (ISWT) and c, d) 6-min walking distance (6MWD).

controls, when exposed to a high-fat diet [39]. In humans, type I to type II fibre shift is associated with both insulin resistance and obesity [40,41], and intramuscular fat is associated with [42] and may exacerbate insulin resistance [43]. Fat within skeletal muscle may also reflect fat tissue elsewhere in the body exceeding its storage capacity and the subsequent release of fatty acids into the circulation. Thus, intramuscular fat may also facilitate a stratified medicine approach as a biomarker of insulin resistance and cardiovascular risk in COPD more generally. The former could be investigated by measures of fasting insulin levels, for example, skeletal muscle adiposity with euglycaemic insulin clamp studies [44], and the latter by prospective observation of cardiovascular events in patients with COPD whose levels of intramuscular fat are known.

Functional exercise performance was also associated with percentage intramuscular fat and skeletal muscle attenuation. Given the link between physical inactivity and muscle fibre shift, this probably reflects reduced quadriceps oxidative capacity and endurance, leading to early fatigue. This consolidates previous data in

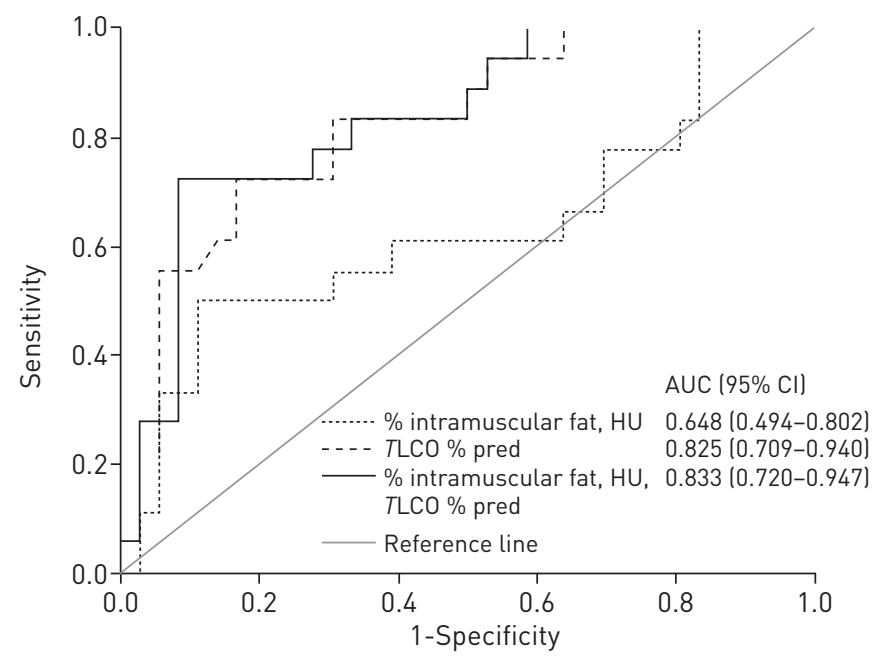

FIGURE 4 Receiver operating characteristic curves for transfer factor of the lung for carbon monoxide (TLCO) \% predicted and measures of skeletal muscle adiposity and areas under the curve (AUC) (95\% CI). Optimal sensitivity/specificity values for the dark solid line: 88.9/50.0\%; 83.3/66.7\%; 77.8/82.2\%; 72.2/91.1\%. 
which our group demonstrated patients with fibre shift had poorer exercise performance than those without, independent of differences in MTCSA and quadriceps strength [25].

\section{Relationship to other work}

Two small studies have previously demonstrated greater levels of intramuscular fat in patients with COPD compared with healthy controls using CT and magnetic resonance imaging [45, 46]. Neither demonstrated an association between measures of skeletal muscle adiposity and functional performance. SHEILDS et al. [47] recently demonstrated increased intermuscular fat, as assessed by magnetic resonance imaging, in the quadriceps of patients with COPD compared with healthy controls (mean increase 32\%). As in the present study, fat infiltration, but not muscle cross-sectional area, was associated with increased anaerobic metabolism during exercise and reduced exercise performance [47]. Bioenergetic changes were not observed in the biceps brachii despite patients having been selected on the basis of weakness in the quadriceps [47].

\section{Critique of the method}

Interobserver and interoccasion agreement for measures of skeletal muscle adiposity based on a standard CT image were excellent, with narrower limits of agreement than those reported during measurement of rectus femoris cross-sectional area with ultrasound [48]. Studies using CT report coefficients of variation between $1.5 \%$ and $2.5 \%$ for tissue cross-sectional area and $<1 \%$ for muscle attenuation [49], with each HU increase equivalent to a $1 \%$ increase in lipid concentration when assessed microscopically [17]. Differences in serial measurements over 3 months in patients with stable COPD were also small and comparable to those found with CT-based measures of muscle or adipose cross-sectional area as confirmed by axial cadaver sections [50,51]. The small measurement differences may be ascribed to operator error, particularly in the manual correction of tissue margins, which are required in the absence of a fully automated analysis procedure. Error relating to image acquisition should be minimal, particularly in comparison to other modalities that rely on surface land-marking, for example ultrasound. Nonetheless, the marginally greater differences between, as compared with within, observers underscores a need for training and standardisation of observers for longitudinal measurements.

Muscle biopsies were obtained in a large subset of subjects in this study. Samples were used for fibre typing, and to measure inflammatory markers and other mediators to fulfil the aims of primary studies. Unfortunately, insufficient tissue remained to stain for intermyocellular and intramyocellular fat deposition, which would have served as criterion measures to validate the CT-based measures as surrogate markers of muscle adiposity. Direct measures of intramyocellular fat and myofilament density, and other measures of muscle phenotype such as capillarisation, oxidative enzyme content and glucose handling, would be helpful to examine in this population.

Future longitudinal work should explore the accumulation and mechanisms of intramuscular fat, the responsiveness to change of these CT-based measurements and their ability to help predict clinical outcome, for example treatment response, risk of admission or cardiovascular events. In older adults, 12 weeks of high-intensity resistance training has been shown to increase quadriceps and hamstring muscle attenuation by $5.4 \%$ and $5.5 \%$, respectively, with concurrent changes in strength and mass [52]. Skeletal muscle attenuation has also been used to predict community-based falls, hip fracture and functional mobility, independent of strength [22, 23].

\section{Conclusion}

In conclusion, skeletal muscle adiposity assessed by CT imaging reflects important aspects of muscle dysfunction in patients with COPD and may help to identify patients with fibre shift. Future work should identify its responsiveness to intervention, both in proven therapies, for example exercise training, and with novel drugs where specific muscle phenotypes may be expected to respond differently.

\section{Acknowledgements}

We thank all patients who kindly agreed to participate in the studies and members of the Lung Function Department at the Royal Brompton Hospital (London, UK) for their testing of study participants.

\section{References}

1 Seymour JM, Spruit M, Hopkinson NS, et al. The prevalence of quadriceps weakness in COPD and the relationship with disease severity. Eur Respir J 2010; 36: 81-88.

2 Kelly JL, Elkin SL, Fluxman J, et al. Breathlessness and skeletal muscle weakness in patients undergoing lung health screening in primary care. COPD 2013; 10: 40-54.

3 Watz H, Waschki B, Boehme C, et al. Extrapulmonary effects of chronic obstructive pulmonary disease on physical activity: a cross-sectional study. Am J Respir Crit Care Med 2008; 177: 743-751.

4 Man WD, Soliman M, Nikoletou D, et al. Non-volitional assessment of skeletal muscle strength in patients with chronic obstructive pulmonary disease. Thorax 2003; 58: 665-669. 
5 Gosselink R, Troosters T, Decramer M. Peripheral muscle weakness contributes to exercise limitation in COPD. Am J Respir Crit Care Med 1996; 153: 976-980.

6 Shrikrishna D, Patel M, Tanner RJ, et al. Quadriceps wasting and physical inactivity in patients with COPD. Eur Respir J 2012; 40: 1115-1122.

7 Decramer M, Gosselink R, Troosters T, et al. Muscle weakness is related to utilization of health care resources in COPD patients. Eur Respir J 1997; 10: 417-423.

8 Swallow EB, Reyes D, Hopkinson NS, et al. Quadriceps strength predicts mortality in patients with moderate to severe chronic obstructive pulmonary disease. Thorax 2007; 62: 115-120.

9 Shrikrishna D, Hopkinson NS. Chronic obstructive pulmonary disease: consequences beyond the lung. Clin Med 2012; 12: 71-74.

10 Swallow EB, Gosker HR, Ward KA, et al. A novel technique for nonvolitional assessment of quadriceps muscle endurance in humans. J Appl Physiol 2007; 103: 739-746.

11 Gosker HR, Zeegers MP, Wouters EF, et al. Muscle fibre type shifting in the vastus lateralis of patients with COPD is associated with disease severity: a systematic review and meta-analysis. Thorax 2007; 62: 944-949.

12 van den Borst B, Slot IG, Hellwig VA, et al. Loss of quadriceps muscle oxidative phenotype and decreased endurance in patients with mild-to-moderate COPD. J Appl Physiol 2013; 114: 1319-1328.

13 Natanek SA, Gosker HR, Slot IG, et al. Heterogeneity of quadriceps muscle phenotype in chronic obstructive pulmonary disease (COPD); implications for stratified medicine? Muscle Nerve 2013; 48: 488-497.

14 Steiner MC, Roubenoff R, Tal-Singer R, et al. Prospects for the development of effective pharmacotherapy targeted at the skeletal muscles in chronic obstructive pulmonary disease: a translational review. Thorax 2012; 67: 1102-1109.

15 Håggmark T, Jansson E, Svane B. Cross-sectional area of the thigh muscle in man measured by computed tomography. Scand J Clin Lab Invest 1978; 38: 355-360.

16 Borkan GA, Hults DE, Gerzof SG, et al. Age changes in body composition revealed by computed tomography. J Gerontol 1983; 38: 673-677.

17 Goodpaster BH, Kelley DE, Thaete FL, et al. Skeletal muscle attenuation determined by computed tomography is associated with skeletal muscle lipid content. J Appl Physiol 2000; 89: 104-110.

18 Simoneau JA, Colberg SR, Thaete FL, et al. Skeletal muscle glycolytic and oxidative enzyme capacities are determinants of insulin sensitivity and muscle composition in obese women. FASEB J 1995; 9: 273-278.

19 Goodpaster BH, Thaete FL, Simoneau JA, et al. Subcutaneous abdominal fat and thigh muscle composition predict insulin sensitivity independently of visceral fat. Diabetes 1997; 46: 1579-1585.

20 Goodpaster BH, Carlson CL, Visser M, et al. Attenuation of skeletal muscle and strength in the elderly: the Health ABC Study. J Appl Physiol 2001; 90: 2157-2165.

21 Visser M, Kritchevsky SB, Goodpaster BH, et al. Leg muscle mass and composition in relation to lower extremity performance in men and women aged 70 to 79: the health, aging and body composition study. J Am Geriatr Soc 2002; 50: 897-904.

22 Visser M, Goodpaster BH, Kritchevsky SB, et al. Muscle mass, muscle strength, and muscle fat infiltration as predictors of incident mobility limitations in well-functioning older persons. J Gerontol A Biol Sci Med Sci 2005; 60: 324-333.

23 Lang T, Cauley JA, Tylavsky F, et al. Computed tomographic measurements of thigh muscle cross-sectional area and attenuation coefficient predict hip fracture: the health, aging, and body composition study. J Bone Miner Res 2010; 25: 513-519.

24 Vestbo J, Hurd SS, Agustí AG, et al. Global strategy for the diagnosis, management, and prevention of chronic obstructive pulmonary disease: GOLD executive summary. Am J Respir Crit Care Med 2013; 187: 347-365.

25 Natanek SA, Gosker HR, Slot IG, et al. Pathways associated with reduced quadriceps oxidative fibres and endurance in COPD. Eur Respir J 2013; 41: 1275-1283.

26 Mourtzakis M, Prado CM, Lieffers JR, et al. A practical and precise approach to quantification of body composition in cancer patients using computed tomography images acquired during routine care. Appl Physiol Nutr Metab 2008; 33: 997-1006.

27 Irving BA, Weltman JY, Brock DW, et al. NIH ImageJ and Slice-O-Matic computed tomography imaging software to quantify soft tissue. Obesity 2007; 15: 370-376.

28 Strandberg S, Wretling ML, Wredmark T, et al. Reliability of computed tomography measurements in assessment of thigh muscle cross-sectional area and attenuation. BMC Med Imaging 2010; 10: 18.

29 Pallas O, Corominas J, Gea J. Degeneración mixoide en los músculos esqueléticos periféricos de pacientes con EPOC grave. Parte de la miopatía periférica? [Is myxoid degeneration in the peripheral skeletal muscles of patients with severe COPD related to peripheral myopathy?]. Arch Bronconeumol 1999; 35: 143.

30 Koechlin C, Maltais F, Saey D, et al. Hypoxaemia enhances peripheral muscle oxidative stress in chronic obstructive pulmonary disease. Thorax 2005; 60: 834-841.

31 Allaire J, Maltais F, LeBlanc P, et al. Lipofuscin accumulation in the vastus lateralis muscle in patients with chronic obstructive pulmonary disease. Muscle Nerve 2002; 25: 383-389.

32 Remels AH, Schrauwen P, Broekhuizen R, et al. Peroxisome proliferator-activated receptor expression is reduced in skeletal muscle in COPD. Eur Respir J 2007; 30: 245-252.

33 Narkar VA, Downes M, Yu RT, et al. AMPK and PPAR $\delta$ agonists are exercise mimetics. Cell 2008; 134: 405-415.

34 Sala E, Roca J, Marrades RM, et al. Effects of endurance training on skeletal muscle bioenergetics in chronic obstructive pulmonary disease. Am J Respir Crit Care Med 1999; 159: 1726-1734.

35 Lewis A, Riddoch-Contreras J, Natanek SA, et al. Downregulation of the serum response factor/miR-1 axis in the quadriceps of patients with COPD. Thorax 2012; 67: 26-34.

36 Rutten EP, Grydeland TB, Pillai SG, et al. Quantitative CT: associations between emphysema, airway wall thickness and body composition in COPD. Pulm Med 2011; 2011: 419328.

37 Hopkinson NS, Nickol AH, Payne J, et al. Angiotensin converting enzyme genotype and strength in chronic obstructive pulmonary disease. Am J Respir Crit Care Med 2004; 170: 395-399.

38 Blomstrand E, Challiss RA, Cooney GJ, et al. Maximal activities of hexokinase, 6-phosphofructokinase, oxoglutarate dehydrogenase, and carnitine palmitoyltransferase in rat and avian muscles. Biosci Rep 1983; 3: $1149-1153$. 
Wang YX, Zhang CL, Yu RT, et al. Regulation of muscle fiber type and running endurance by PPAR $\delta$. PLoS Biol 2004; 2: e294

40 Lillioja S, Young AA, Culter CL, et al. Skeletal muscle capillary density and fiber type are possible determinants of in vivo insulin resistance in man. J Clin Invest 1987; 80: 415-424.

41 Oberbach A, Bossenz Y, Lehmann S, et al. Altered fiber distribution and fiber-specific glycolytic and oxidative enzyme activity in skeletal muscle of patients with type 2 diabetes. Diabetes Care 2006; 29: 895-900.

42 Phillips DI, Caddy S, Ilic V, et al. Intramuscular triglyceride and muscle insulin sensitivity: evidence for a relationship in nondiabetic subjects. Metabolism 1996; 45: 947-950.

43 Hegarty BD, Furler SM, Ye J, et al. The role of intramuscular lipid in insulin resistance. Acta Physiol Scand 2003; 178: 373-383.

44 van den Borst B, Gosker HR, Schols AM. Central fat and peripheral muscle: partners in crime in chronic obstructive pulmonary disease. Am J Respir Crit Care Med 2013; 187: 8-13.

45 Roig M, Eng JJ, MacIntyre DL, et al. Deficits in muscle strength, mass, quality and mobility in people with chronic obstructive pulmonary disease. J Cardiopulm Rehabil Prev 2011; 31: 120-124.

46 Mathur S, MacIntyre DL, Forster BB, et al. Preservation of eccentric torque of the knee extensors and flexors in patients with COPD. J Cardiopulm Rehabil Prev 2007; 27: 411-416.

47 Shields GS, Coissi GS, Jimenez-Royo P, et al. Bioenergetic abnormailites and intermuscular fat in chronic obstructive pulmonary disease (COPD)-associated quadricpes weakness. Muscle Nerve 2014 [In press DOI: 10.1002/ mus.24289].

48 Seymour JM, Ward K, Sidhu PS, et al. Ultrasound measurement of rectus femoris cross-sectional area and the relationship with quadriceps strength in COPD. Thorax 2009; 64: 418-423.

49 MacDonald AJ, Greig CA, Baracos V. The advantages and limitations of cross-sectional body composition analysis. Curr Opin Support Palliat Care 2011; 5: 342-349.

50 Hudash G, Albright JP, McAuley E, et al. Cross-sectional thigh components: computerized tomographic assessment. Med Sci Sports Exerc 1985; 17: 417-421.

51 Mitsiopoulos N, Baumgartner R, Heymsfield S, et al. Cadaver validation of skeletal muscle measurement by magnetic resonance imaging and computerized tomography. J Appl Physiol 1998; 85: 115-122.

52 Taaffe DR, Henwood TR, Nalls MA, et al. Alterations in muscle attenuation following detraining and retraining in resistance-trained older adults. Gerontology 2009; 55: 217-223. 